\title{
Women's childhood and adult adverse experiences, mental health, and binge drinking: The California Women's Health Survey Christine Timko*1,2, Anne Sutkowi ${ }^{1}$, Joanne Pavao ${ }^{3}$ and Rachel Kimerling ${ }^{1,3}$
}

Address: ${ }^{1}$ Center for Health Care Evaluation, Department of Veterans Affairs (VA) Health Care System, 795 Willow Road, Menlo Park, CA 94025, USA, ${ }^{2}$ Department of Psychiatry and Behavioral Sciences, Stanford University, Stanford, CA 94305, USA and ${ }^{3}$ National Center for PTSD, VA Health Care System, 795 Willow Road, Menlo Park, CA 94025, USA

Email: Christine Timko* - ctimko@stanford.edu; Anne Sutkowi - Anne.Sutkowi@va.gov; Joanne Pavao - Joanne.Pavao@va.gov; Rachel Kimerling - Rachel.Kimerling@va.gov

* Corresponding author

\section{Published: 6 June 2008}

Substance Abuse Treatment, Prevention, and Policy 2008, 3:15 doi:10.1 186/I747-597X-315

This article is available from: http://www.substanceabusepolicy.com/content/3/1/15

(C) 2008 Timko et al; licensee BioMed Central Ltd.

This is an Open Access article distributed under the terms of the Creative Commons Attribution License (http://creativecommons.org/licenses/by/2.0), which permits unrestricted use, distribution, and reproduction in any medium, provided the original work is properly cited.

\begin{abstract}
Background: This study examined sociodemographic, physical and mental health, and adult and childhood adverse experiences associated with binge drinking in a representative sample of women in the State of California.
\end{abstract}

Materials and methods: Data were from the 2003 to 2004 (response rates of $72 \%$ and 74\%, respectively) California Women's Health Survey (CWHS), a population-based, random-digit-dial annual probability survey sponsored by the California Department of Health Services. The sample was 6,942 women aged 18 years or older.

Results: The prevalence of binge drinking was 9.3\%. Poor physical health, and poorer mental health (i.e., symptoms of PTSD, anxiety, and depression, feeling overwhelmed by stress), were associated with binge drinking when demographics were controlled, as were adverse experiences in adulthood (intimate partner violence, having been physically or sexually assaulted, or having experienced the death of someone close) and in childhood (living with someone abusing substances or mentally ill, or with a mother vicimized by violence, or having been physically or sexually assaulted). When adult mental health and adverse experiences were also controlled, having lived as a child with someone who abused substances or was mentally ill was associated with binge drinking. Associations between childhood adverse experiences and binge drinking could not be explained by women's poorer mental health status in adulthood.

Conclusion: Identifying characteristics of women who engage in binge drinking is a key step in prevention and intervention efforts. Binge drinking programs should consider comprehensive approaches that address women's mental health symptoms as well as circumstances in the childhood home.

\section{Background}

Binge drinking has been linked to a broad range of health and psychosocial problems. Although definitions of binge drinking vary somewhat among studies, a commonly used definition for women and men is that of the Centers for Disease Control and Prevention's (CDC) Behavioral 
Risk Factor Surveillance System: five drinks per drinking occasion at least once during the past 30 days. Rates of binge drinking are lower among women than men across different age and racial/ethnic groups [1-3]. The rates of binge drinking among women have remained stable over the past two decades [4].

It is important to understand the determinants of binge drinking among women because higher rates of binge drinking are linked to increases in alcohol use disorders, injuries and other alcohol-related health problems (including poor health outcomes among babies born to alcohol abusing mothers), psychosocial problems, and high-risk behaviors (e.g., smoking, having multiple sexual partners) [5]. This study examined the rate of binge drinking and factors associated with binge drinking in a representative sample of women in California. We looked at factors in five domains in addition to sociodemographic characteristics: physical health, mental health, help with mental health problems, adverse adult experiences, and adverse childhood experiences. We also examined whether adverse childhood experiences were related to binge drinking as an adult, when adverse experiences and symptoms of poor mental health in adulthood were considered. The purpose was to indicate whether negative childhood experiences may predict binge drinking among adult women above and beyond more recent and current problems. Our goal is to help build binge-drinking prevention and intervention programs that are specific to women by targeting the factors associated with binge drinking.

\section{Characteristics of women who binge drink}

A number of studies have examined sociodemographic factors associated with women's binge drinking. Binge drinking is more common among younger ( $<30$ years) women [6] and binge drinking as a younger woman increases the odds of binge drinking in middle age [7]. In addition, binge drinking is more likely among unmarried and less educated women [5], although studies of highly educated employees found binge drinking rates among women to be high $[8,9]$. Binge drinking was more common among White and mixed-race than among Hispanic, Black, or Asian women [6]. It is also known to be more common among American Indian women than women in other racial/ethnic groups [10,11]. Rates of binge drinking were higher among non-pregnant than pregnant women [6]. In the domain of mental health, higher rates of posttraumatic stress disorder (PTSD), anxiety, and depression were associated with more binge drinking [5]. In contrast, another study found that women with anxiety and depression had reduced odds of binge drinking [1].

Female victims of violence often engage in self-destructive and maladaptive coping behaviors, including binge drink- ing. Increased rates of domestic violence among women were associated with increased binge drinking rates [5]. Similarly, women's rates of binge drinking increased from $5.5 \%$ among those with no lifetime history of intimate partner violence (IPV), to $12.1 \%$ among those with a low level of IPV, to $16.8 \%$ among those with a moderate or high level [12]. Binge drinking may occur as a form of selfmedication to alleviate symptoms of trauma, anxiety, and depression, and increase feelings of mastery and control [13].

Adverse experiences in childhood also increase the risk for the subsequent problematic use of alcohol such as binge drinking. Childhood sexual abuse was an important predictor of alcohol misuse and binge drinking among adult women $[14,15]$, and adolescent victims of sexual and/or physical assault were more likely than controls to subsequently engage in binge drinking [13]. Each of eight kinds of adverse childhood experiences (verbal, physical, and sexual abuse, had a battered mother, lived with problem drinker/alcoholic or user of street drugs, mental illness in the household, parental separation or divorce, incarcerated household member) was associated with a higher risk of alcohol abuse in a sample of adult women and men [16].

Although adverse childhood experiences have been found to be associated with problematic alcohol use such as binge drinking, studies have not examined whether the childhood events are associated with alcohol misuse even when adult life events and circumstances are also considered. In addition, they have not examined whether poor mental health as an adult mediates the link between adverse childhood experiences and adult binge drinking, as some have hypothesized [17]. Both of these possibilities are important to explore because they have implications for the prevention and treatment of binge drinking. If adverse childhood experiences contribute to binge drinking when concurrent adult functioning is accounted for, and the association of adverse childhood experiences with binge drinking is not fully explained by its impact on poorer adult mental health, then specialized treatment for adverse childhood experiences must be integrated into clinical approaches used in preventing and treating binge drinking.

In summary, in this study we asked the following questions: (1) What is the rate of binge drinking in a representative sample of women in the State of California, (2) What are the sociodemographic, physical and mental health, and adverse adult and childhood experiences associated with binge drinking, (3) Are adverse childhood experiences associated with binge drinking, even when adverse adult experiences and mental health symptoms are already accounted for, and (4) Does poorer adult men- 
tal health mediate the association between adverse childhood experiences and adult binge drinking among women.

\section{Materials and Methods}

All procedures for this study were reviewed and approved by Stanford University's Institutional Review Board. We used data from the 2003 and 2004 California Women's Health Survey (CWHS), a population-based, randomdigit-dial (not including cell phones) annual probability survey sponsored by the California Department of Health Services and designed in collaboration with several other state agencies and departments. Interviews for the CWHS are conducted in English or Spanish and take approximately 30 minutes to complete.

The response rates for the surveys (i.e., the proportions of eligible households contacted that resulted in a completed interview) were $72 \%$ and $74 \%$, respectively. The combined 2-year sample consisted of 6,942 women aged 18 years or older. More detailed information about the sample procedures can be found in [18].

\section{Measures}

\section{Binge drinking}

Respondents were asked: Considering all types of alcoholic beverages, how many times during the past month did you have five or more drinks on an occasion? Following the CDC definition used prior to 2006, respondents who reported doing so one time or more were classified as binge drinkers; all other respondents, including abstainers, were classified as non-binge drinkers.

\section{Sociodemographics}

Respondents reported their age, race and ethnicity, marital status, whether children were in the household, education, and employment status. Respondents' reports of household size and annual household income were used to determine whether they were above or below the federal poverty line [19].

\section{Physical health}

The interview asked: To your knowledge, are you now pregnant (yes/no). It also asked: Do you now smoke cigarettes. Answers were classified as yes (every day or some days) or no (not at all). Respondents' self-reported health was classified as good (i.e., good, very good, or excellent) or fair/poor.

\section{Mental health}

Symptoms of PTSD were assessed using a five-item screen, demonstrated by Prins et al. [20] to detect current (past 30 days) and clinically significant PTSD symptoms. One item is a general trauma probe in which the interviewer asks if the respondent has ever, in her lifetime, had any experi- ence or experiences that are frightening, horrible or upsetting. Four more items assess the presence or absence of the following PTSD symptoms: intrusive trauma-related thoughts, avoidance of trauma-related cues, emotional numbing, and physiological hyperarousal. Respondents were coded positive for PTSD symptoms if they screened positive for trauma and endorsed $\geq 3$ PTSD items. To assess depression, respondents were asked to report how many of the past 30 days they felt sad, blue, or depressed; and to assess anxiety, they reported how many days they felt worried, tense, or anxious. These items were from the healthy days measure used in the Brief Behavioral Risk Factor Survey [21]. Respondents were coded positive for depression or anxiety if they reported symptoms on $\geq 14$ days of the past 30 days.

\section{Mental health help}

Poor mental health was assessed by asking respondents to report how many days during the past 30 their mental health (e.g., problems with emotions) was not good. Respondents were coded positive for poor mental health if they reported that their mental health was not good on $\geq 14$ days. In addition, respondents reported whether they had wanted or needed help with personal or family problems from a mental health professional in the past 12 months (yes/no), and whether they had obtained such help (yes/no).

\section{Adverse adult experiences}

CWHS questions on adverse adult and childhood experiences were from the Traumatic Stress Schedule, a validated self-report measure of traumatic events [22], and subjected to cognitive testing for use in telephone surveys. Respondents reported whether, during the past 12 months, they had experienced intimate partner violence. Specifically, if the respondent answered yes to one or more of 8 items (e.g., partner or former partner had thrown something at her; had pushed, grabbed, shoved, or slapped her), she was classified as having experienced intimate partner violence. Respondents also reported whether they experienced the following adverse experiences during their adulthood (age 18 or after): physical assault (i.e., was beaten up, slapped, punched, kicked, or attacked by a stranger or someone known), sexual assault (i.e., was forced into unwanted sexual activity), or death of a close friend or family member in an accident, homicide, or suicide.

\section{Adverse childhood experiences}

Respondents reported whether they experienced the following adverse experiences during their childhood (before age 18): was removed from home and placed in foster care; lived with someone who was a problem drinker or alcoholic or used street drugs; lived with someone who was depressed or mentally ill; mother or step- 
mother was treated violently; lived with someone who went to prison or jail; emotional abuse (i.e., adult in household often or very often swore at, insulted, put down, or made her afraid that she would be physically hurt); physical assault (i.e., was beaten up, slapped, punched, kicked, or attacked by a stranger or someone known); and sexual assault (i.e., was forced into unwanted sexual activity).

\section{Analyses}

The first set of logistic regression analyses examined associations of sociodemographic factors (each entered singly as an independent variable) with binge drinker status. Then, we conducted logistic regression analyses that controlled for the sociodemographic factors found to be significantly associated with binge drinking, and entered one factor (i.e., one variable) in the domain of physical health, mental health, mental health help, adverse adult experiences, or adverse childhood experiences as a predictor. A third set of logistic regressions examined associations of adverse childhood experiences with binge drinking when sociodemographic, adult mental health, and adverse adult experiences that were significantly associated with binge drinking were controlled; the purpose was to determine whether adverse childhood experiences were independently associated with binge drinking after more recent adverse experiences and mental health symptoms as adults were considered. Finally, we conducted a series of regression analyses to determine whether poorer adult mental health mediated between adverse childhood experiences and binge drinking.

\section{Results}

The prevalence of binge drinking was 9.3\%. The other sample characteristics are presented in Table 1 . We first compared binge drinkers $(n=647)$ to non-binge drinkers $(n=6,295)$ on demographics (Table 2). Because binge drinkers were younger and more likely to be unmarried and unemployed, and were somewhat more likely to have an income below the federal poverty line, we controlled for these variables in all subsequent analyses.
Table I: Sample characteristics

\begin{tabular}{ll}
\hline Sociodemographics & \% of full sample \\
\hline Age (mean, SD) & $32.6,13.0$ \\
Minority/racial group member & 50.2 \\
Not married & 45.0 \\
No. children in household & 49.6 \\
No education beyond high school & 37.4 \\
Not employed & 45.4 \\
Income below federal poverty line & 17.9 \\
Physical health & \\
Not pregnant & 94.7 \\
Smokes & 13.6 \\
Fair/poor health & 17.3 \\
Mental health & \\
PTSD symptoms & 6.3 \\
Anxiety symptoms & 21.8 \\
Depression symptoms & 13.7 \\
Overwhelmed by stress & 12.5 \\
Mental health help & \\
Poor mental health & 14.2 \\
Perceived need for mental health help & 23.2 \\
Utilized mental health help & 9.8 \\
Adult victimization & \\
Intimate partner violence & \\
Physically assaulted & 9.9 \\
Sexually assaulted & 19.7 \\
Death of someone close & 10.6 \\
Childhood victimization & 29.7 \\
Lived in foster care & 3.4 \\
Lived with someone abusing substances & 22.3 \\
Lived with someone mentally ill & 16.8 \\
Lived with mother victimized by violence & 18.4 \\
Lived with someone incarcerated & 7.6 \\
Emotionally abused by adult in home & 18.4 \\
Physically assaulted & 19.1 \\
Sexually assaulted & 11.2 \\
\hline & \\
\hline &
\end{tabular}

Logistic regressions predicting binge drinking from current physical and mental health, and help for mental health problems in the past year, found a significant association for each factor (Table 3). Specifically, binge drinking was associated with not having a current pregnancy, currently smoking, and being in fair or poor rather than

Table 2: Logistic regressions predicting binge $(n=647)$ versus non-binge $(n=6295)$ drinker status from sociodemographics

\begin{tabular}{|c|c|c|c|c|}
\hline \multirow[b]{2}{*}{ Sociodemographics } & \multicolumn{4}{|c|}{ Binge drinker } \\
\hline & $\underline{B}$ & $\underline{\mathrm{OR}}$ & $95 \% \mathrm{Cl}$ & $p$ \\
\hline Age (mean, SD) & -.477 & .621 & $.58-.66$ & $<.001$ \\
\hline Minority racial/ethnic group member & .084 & 1.087 & $.93-1.28$ & .311 \\
\hline Not married & .980 & 2.664 & $2.25-3.16$ & $<.001$ \\
\hline No children in household & .135 & $\mathrm{I} .144$ & $.97-1.35$ & .104 \\
\hline No education beyond high school & .017 & 1.018 & $.86-1.20$ & .838 \\
\hline Not employed & .429 & 1.535 & $1.30-1.82$ & $<.001$ \\
\hline Income below federal poverty line & .180 & 1.197 & $.98-1.46$ & .081 \\
\hline
\end{tabular}

Note: Each $p$-value is from a Wald $X^{2}(d f=1)$. 
Table 3: Logistic regressions predicting binge $(n=647)$ or non-binge $(n=6295)$ drinker status from physical and mental health and mental health help, controlling for sociodemographics

\begin{tabular}{|c|c|c|c|c|}
\hline & \multicolumn{4}{|c|}{ Binge drinker } \\
\hline & $\underline{B}$ & $\underline{\mathrm{OR}}$ & $\underline{95 \% \mathrm{Cl}}$ & p \\
\hline \multicolumn{5}{|l|}{ Physical Health } \\
\hline Not pregnant & 2.288 & 9.859 & $3.40-28.59$ & $<.001$ \\
\hline Smokes & .985 & 2.679 & $2.21-3.25$ & $<.001$ \\
\hline Fair/Poor health & .287 & 1.333 & $1.10-1.76$ & .041 \\
\hline \multicolumn{5}{|l|}{ Mental health } \\
\hline PTSD symptoms & .787 & 2.197 & $1.69-2.86$ & $<.001$ \\
\hline Anxiety symptoms & .478 & 1.614 & $1.34-1.94$ & $<.001$ \\
\hline Depression symptoms & .497 & 1.644 & $1.33-2.04$ & $<.001$ \\
\hline Overwhelmed by stress & .613 & 1.846 & $1.50-2.28$ & $<.001$ \\
\hline \multicolumn{5}{|l|}{ Mental health help } \\
\hline Poor mental health & .484 & 1.622 & $1.31-2.00$ & $<.001$ \\
\hline Perceived need for mental health help, past year & .305 & 1.357 & $1.13-1.63$ & .001 \\
\hline Utilized mental health help, past year & .479 & 1.614 & $1.19-2.20$ & .002 \\
\hline
\end{tabular}

Note: Each $p$-value is from a Wald $X^{2}(d f=I)$.

good health. In the mental health domain, symptoms of PTSD, anxiety, and depression, as well as feeling overwhelmed by stress, were associated with binge drinking. Consistently, poor mental health, and perceiving the need for and utilizing mental health help in the past year, were associated with binge drinker status. As expected, binge drinking was associated with adverse experiences in adulthood (intimate partner violence, having been physically or sexually assaulted, or having experienced the death of someone close) and in childhood (living with someone abusing substances or mentally ill, or with a mother vic- timized by violence, and having been physically or sexually assaulted) (Table 4).

Because, as already noted, binge drinking is more common in younger age groups, we examined whether age was a moderator of associations between physical and mental health, mental health help, and adult and childhood adverse experiences and binge drinking. Specifically, we conducted each logistic regression in Tables 3 and 4 , adding the interaction of age by the predictor. The interactions of age by poor mental health $(B=-.272$, OR

Table 4: Logistic regressions predicting binge $(n=647)$ or non-binge $(n=6295)$ drinker status from adult and childhood adverse experiences, controlling for sociodemographics

\begin{tabular}{|c|c|c|c|c|}
\hline & \multicolumn{4}{|c|}{ Binge drinker } \\
\hline & $\underline{B}$ & $\underline{O R}$ & $\underline{95 \% \mathrm{Cl}}$ & $p$ \\
\hline \multicolumn{5}{|l|}{ Adult adverse experiences } \\
\hline Intimate partner violence & .542 & 1.719 & $1.37-2.15$ & $<.001$ \\
\hline Physically assaulted & .670 & 1.954 & $1.6 \mathrm{I}-2.36$ & $<.001$ \\
\hline Sexually assaulted & .279 & 1.321 & $|.02-1.7|$ & .035 \\
\hline Death of someone close & .641 & 1.898 & $1.60-2.25$ & $<.001$ \\
\hline \multicolumn{5}{|l|}{ Childhood adverse experiences } \\
\hline Lived in foster care & .288 & $\mathrm{I} .334$ & $.90-1.99$ & .157 \\
\hline Lived with someone abusing substances & .480 & 1.616 & $1.35-1.94$ & $<.001$ \\
\hline Lived with someone mentally ill & .594 & $1.81 \mathrm{I}$ & $1.50-2.19$ & $<.001$ \\
\hline Lived with mother victimized by violence & .587 & 1.799 & $1.36-2.39$ & $<.001$ \\
\hline Lived with someone incarcerated & .191 & 1.210 & $.93-1.58$ & .161 \\
\hline Emotionally abused by adult in home & .421 & 1.523 & $1.26-1.85$ & $<.001$ \\
\hline Physically assaulted & .513 & $1.67 \mid$ & I.39-2.0। & $<.001$ \\
\hline Sexually assaulted & .424 & 1.527 & $1.21-1.92$ & $<.001$ \\
\hline
\end{tabular}

Note: Each $\mathrm{p}$-value is from a Wald $X^{2}(d f=1)$. 
$=.762, \mathrm{CI}=.63-.72$, Wald $\left.X^{2}=9.14, d f=1, p=.003\right)$ and by having lived with someone mentally ill $(B=-.163$, OR$.850, \mathrm{CI}=.73-.99$, Wald $\left.X^{2}=4.03, d f=1, p=.045\right)$ in predicting binge drinking were significant. There were positive associations of poor mental health and having lived with someone mentally ill with binge drinking in each age group except for the oldest group. That is, among women 65 years old or older only, poor mental health and having lived with someone mentally ill were associated with nonbinge drinker status.

We examined whether adverse childhood experiences were still associated with binge drinking when mental health (PTSD, anxiety, depression, overwhelmed) and adverse experiences (intimate partner violence, physical assault, sexual assault, death of someone close) in adulthood were controlled (Table 5). When adulthood factors were also considered, the childhood experiences of having lived with someone who abused substances or who was mentally ill were associated with binge drinking. Specifically, these childhood experiences were associated with roughly double the likelihood of binge drinking. Binge drinking occurred in $14 \%$ of women who lived with an individual abusing substances, and in $8 \%$ of women who did not. And, binge drinking occurred in $16 \%$ of women who lived with an individual who was mentally ill, and in $8 \%$ of women who did not.

Finally, we examined whether poor mental health as an adult mediated associations between adverse childhood experiences and adult binge drinking. First, we created two new dichotomous variables reflecting adverse childhood experiences: (1) lived with a person who abused substances and/or was mentally ill and/or a mother victimized by violence (50.3\%) or not, and (2) was emotionally abused, physically assaulted, or sexually assaulted $(33.7 \%)$ or not. Regressions showed that living with a disordered/victimized person predicted binge drinking, as did childhood abuse/assault (Table 6).
To examine mediation, first, poor mental health (the potential mediator) was the dependent variable in regressions using the new variables as predictors. Living with a disordered or victimized person was associated with poor mental health, as was having been abused or assaulted (Table 6). As already noted (Table 4), poor mental health was associated with binge drinking. A logistic regression predicting binge drinker status from both living with a disordered/victimized person and poor mental health found that both factors retained significant associations with binge drinking (Table 6). Finally, a logistic regression predicting binge drinker status from both childhood abuse/assault and poor mental health also found that both factors retained significant associations (Table 6). That is, adverse childhood experiences represented by living with others' or their own difficult life circumstances retained independent associations with women's binge drinking and was not mediated by poorer mental health status in adulthood.

\section{Discussion}

The CWHS found that the prevalence of binge drinking among adult women in California was $9.3 \%$. This is similar to findings from national surveys of the US population in which $7.3 \%$ to $11.8 \%$ of women reported drinking five or more drinks on an occasion in the past month $[2,23,24]$.

Compared to women who did not binge drink, binge drinking women were less likely to be pregnant, and more likely to smoke cigarettes and to describe themselves as only in fair or poor health. These results agree with those from other studies that pregnancy is associated with less binge drinking whereas smoking is associated with more binging on alcohol $[25,26]$. One survey found that $38 \%$ of young women reported smoking as the main reason for drinking [27]. Young women who both binge drank and smoked were especially likely to report depressive symptoms [28].

Table 5: Logistic regressions predicting binge $(n=647)$ or non-binge $(n=6295)$ drinker status from childhood adverse experiences, controlling for sociodemographics, mental health, and adult adverse experiences

\begin{tabular}{|c|c|c|c|c|}
\hline \multirow[b]{2}{*}{ Childhood adverse experiences } & \multicolumn{4}{|c|}{ Binge drinker } \\
\hline & $\underline{B}$ & $\underline{O R}$ & $\underline{95 \% \mathrm{Cl}}$ & $p$ \\
\hline Lived in foster care & .044 & 1.045 & $.69-1.58$ & .835 \\
\hline Lived with someone abusing substances & .241 & 1.273 & $1.05-1.55$ & .015 \\
\hline Lived with someone mentally ill & .359 & 1.431 & $1.17-1.76$ & .001 \\
\hline Lived with mother victimized by violence & -.050 & .951 & $.70-1.29$ & .744 \\
\hline Lived with someone incarcerated & -.121 & .886 & $.67-1.17$ & .396 \\
\hline Emotionally abused by adult in home & .073 & 1.075 & $.87-1.34$ & .514 \\
\hline Physically assaulted & .188 & 1.206 & $.98-1.49$ & .081 \\
\hline Sexually assaulted & .094 & 1.099 & $.85-1.42$ & .464 \\
\hline
\end{tabular}

Note: Each $\mathrm{p}$-value is from a Wald $X^{2}(d f=1)$. 
Table 6: Logistic regressions to examine adult mental health as a mediator between childhood adverse experiences and binge drinking.

\begin{tabular}{|c|c|c|c|c|}
\hline \multirow[b]{2}{*}{ Childhood experiences } & \multicolumn{4}{|c|}{ Binge drinker } \\
\hline & $\underline{B}$ & $\underline{\mathrm{OR}}$ & $\underline{95 \% \mathrm{Cl}}$ & $p$ \\
\hline Living with a disordered/victimized person & 0.609 & 1.84 & $1.25-1.88$ & $<0.001$ \\
\hline \multirow[t]{2}{*}{ Abuse/assault } & 0.578 & 1.78 & $1.47-2.06$ & $<0.001$ \\
\hline & \multicolumn{4}{|c|}{ Adult poor mental health } \\
\hline Living with a disordered/victimized person & 0.964 & 2.62 & $2.20-3.13$ & $<0.001$ \\
\hline Abuse/assault & 1.028 & Binge drinker & $\begin{array}{c}2.43-3.22 \\
\text { Binge drir }\end{array}$ & $<0.001$ \\
\hline Childhood living with a disordered/victimized person & 0.380 & 1.46 & $1.19-1.80$ & $<.001$ \\
\hline Adult poor mental health & 0.309 & 1.36 & $\begin{array}{c}1.06-1.75 \\
\text { Binge drir }\end{array}$ & 0.016 \\
\hline Childhood abuse/assault & 0.500 & 1.65 & $1.39-1.96$ & $<0.001$ \\
\hline Adult poor mental health & 0.357 & 1.43 & $1.15-1.78$ & 0.001 \\
\hline
\end{tabular}

Note: Each $p$-value is from a Wald $X^{2}(d f=1)$.

We found that about $13 \%-14 \%$ of the women in this sample had symptoms of depression or overwhelming stress, whereas symptoms of PTSD were less common and symptoms of anxiety were reported by $22 \%$ of women. Having symptoms of depression, stress, PTSD, and anxiety were each associated with binge drinking. The association between depression and alcohol misuse has been relatively well-documented in the literature. For example, analyses of the Canadian National Population Health Survey found an association of major depression and binge drinking among women [29]. In a sample of 121 alcoholdependent women, $31 \%$ were diagnosed with depression, and $46 \%$ with anxiety, suggesting that women often alleviate stress through drinking [30]. Consistently, we found that women's self-reports of poor mental health, and having perceived the need for and utilized help for mental health problems in the past year, were associated with binge drinking.

As expected, binge drinking was associated with adverse experiences both in adulthood and in childhood. For adult victimization by intimate partner violence or sexual assault in particular, drinking is often a maladaptive means of coping with the traumatic aftermath [31-34]. When victimization by such traumatic events is chronic, binge drinking may be explained by PTSD symptoms $[35,36]$. That is, alcohol may be used to medicate PTSDrelated sleep difficulties, hyperarousal, and other symptoms $[37,38]$.

Victimizing childhood experiences have been consistently linked to problems in childhood that extend into adulthood [39-41]. For example, there was a strong association between adverse childhood experiences such as physical and sexual assault and drug abuse in young women [42]. In addition, longitudinal studies found that mothers' depressive symptoms and history of victimization predicted poorer behavioral outcomes among the children, and that the risk of child behavior problems increased with the number of areas B substance use, mental health, or domestic violence $B$ in which the mother reported difficulties [43,44]. Although the CWHS did not assess respondents' recollections of their psychiatric symptoms in childhood, possibly, those whose mothers had psychiatric difficulties or victimizing experiences had more dysfunction in childhood that then persisted into adulthood. Unfortunately, increased rates of binge drinking associated with childhood and adult victimization may increase the risk for re-victimization [45].

Even after adulthood factors were considered, the childhood experiences of having lived with someone who abused substances $(22.3 \%$ of the sample did so) or who was mentally ill ( $16.8 \%$ did so) were still associated with binge drinking. Problematic alcohol use is known to be influenced by problematic parental drinking and a family history of alcoholism [46]. While alcoholism has distinct biological and genetic influences [46-48], parental heavydrinking norms and approval of, or lack of attention to, offspring drinking are also important correlates of risky drinking behaviors and poorer drinking outcomes [4951]. The risk conferred by living with a dysfunctional adult suggests possible benefits of family-oriented medical and mental health care. Whether providers are initially focused on the adult or the child, there is the potential to help disrupt intergenerational alcohol misuse by considering the entire family or at least the parent-offspring dyad.

Importantly, we found that adverse childhood experiences represented by living in the midst of others' or one's own difficult life circumstances retained independent 
associations with women's binge drinking and was not mediated by poorer mental health status in adulthood. Thus it may not always be enough to intervene only with binge drinking, or even with the depression and anxiety also associated with binge drinking. Rather, providers working with binge drinkers should consider asking whether adverse childhood experiences have occurred (in this sample, one-half of women lived with an ill or victimized person in their childhood home, and one-third were personally abused or assaulted as children), and then addressing any consequences of such adverse experiences if they have taken place. Research on trauma-focused therapy for women who were victimized in childhood that has shown promise for improving mental health symptoms [52-54] needs to be extended to alcohol and drug outcomes.

\section{Limitations and Conclusion}

The findings must be considered in light of the methods used. The definition of binge drinking was based on a quantitative cut point that did not consider individual factors that affect blood alcohol concentrations (e.g., weight, drinking history, other drugs ingested). Although a clinically-focused definition (e.g., feelings of intoxication) may have produced different results, consuming five or more drinks on a single occasion usually results in intoxication and impairment [55].

Self-reports as used here may somewhat underestimate alcohol consumption compared with diagnostic interviews, but they typically provide more accurate data than laboratory tests and collateral reports [56]. The data on women's health and binge drinking were cross-sectional, and so cause and effect cannot be determined from these results. Because data on adverse experiences as children and adults were retrospective, it is possible that recall bias influenced self-reports. However, previous research suggests that negative experiences in childhood tend to be under- rather than over-reported [57-59], perhaps leading to an underestimation of the strength of associations between childhood and adult hardship and binge drinking. An additional limitation is that the CWHS did not obtain diagnostic information with regard to physical health, PTSD, anxiety, and depression. Although CWHS items were selected from previously conducted national or statewide surveys for comparability, our findings need replication with more sensitive and precise measures of self-perceived physical and mental health.

Identifying characteristics that are commonly found among women who engage in binge drinking is a key step in designing and implementing effective prevention and intervention efforts. Binge drinking prevention programs perhaps should attend to adult mental health symptoms as well as dynamics in the childhood home. Experts work- ing to decrease binge drinking may consider screening for addiction and other psychiatric disorders reported in the childhood home as well as other types of adverse childhood experiences and then addressing the trauma and other consequences of those stressors. Findings that childhood abuse is associated with poor substance use disorder treatment outcomes in adulthood [60] underscore the need to examine comprehensive and integrated approaches to prevent continued binge drinking.

\section{Competing interests}

The authors declare that they have no competing interests.

\section{Authors' contributions}

All the authors contributed to the design of the study and the analysis and interpretation of data, RK and JP helped to design and acquire data from the CWHS, CT managed the literature searches and wrote the first draft of the manuscript, AS managed the analyses. All authors contributed to and approved the final manuscript.

\section{Acknowledgements}

This project was funded by the VA Office of Research and Development (Health Services Research and Development Service, RCS 00-00I). We thank Rudolf Moos for comments on an earlier draft. The opinions expressed here are the authors' and do not necessarily represent the views of the Department of Veterans Affairs.

\section{References}

I. Haynes JC, Farrell M, Singleton N, Meltzer H, Araya R, Lewis G, Wiles $\mathrm{NJ}$ : Alcohol consumption as a risk factor for anxiety and depression. Br J Psychiatry 2005, I 87:544-55I.

2. Naimi TS, Brewer RD, Mokdad A, Denny C, Serdula MK, Marks JS: Binge drinking among US adults. JAMA 2003, 289:70-75.

3. Wiscott $R$, Kopera-Frye K, Begovic A: Binge drinking in later life: Comparing young-old and old-old social drinkers. Psychol Addict Behav 2002, 16:252-255.

4. Mack KA, Ahluwalia IB: Monitoring women's health in the United States: Selected chronic disease indicators, | 99 |-200| BRFSS. J Womens Health 2003, | 2(4):309-3 |4.

5. Bradley KA, Bush KR, Davis TM, Dobie DJ, Burman ML, Rutter CM, Kivlahan DR: Binge drinking among female Veterans Affairs patients: Prevalence and associated risks. Psychol Addict Behav 2001, I 5:297-305.

6. Caetano R, Ramisetty-Mikler S, Floyd LR, McGrath C: The epidemiology of drinking among women of child-bearing age. Alcohol Clin Exp Res 2006, 30: 1023-1030.

7. Jefferis BJMH, Power C, Manor O: Adolescent drinking level and adult binge drinking in a national birth cohort. Addiction 2005, 1 00:543-549.

8. Matano RA, Koopman C, Wanat SF, Whitsell S, Borggrefe A Westrup D: Assessment of binge drinking of alcohol in highly educated employees. Addict Behav 2003, 28: $1299-1310$.

9. Matano RA, Wanat SF, Westrup D, Koopman C, Whitsell SD: Prevalence of alcohol and drug use in a highly educated workforce. J Behav Health Serv Res 2002, 29:30-44.

10. Bursac Z, Campbell JE: From risky behaviors to chronic outcomes: Current status and Healthy People 2010 goals for American Indians in Oklahoma. J Okla State Med Assoc 2003, 96:569-573.

II. Denny CH, Holtzman D, Cobb N: Surveillance for health behaviors of American Indians and Alaska Natives. MMWR Surveill Summ 2003, 52(7): I- 13.

12. McNutt L, Carlson BE, Persaud M, Postmus J: Cumulative abuse experiences, physical health and health behaviors. Ann Epidemiol 2002, I 2:123-130. 
13. Kaukinen C: Adolescent victimization and problem drinking. Violence Vict 2002, 17:669-689.

14. Galaif ER, Stein JA, Newcomb MD, Bernstein DP: Gender differences in the prediction of problem alcohol use in adulthood: Exploring the influence of family factors and childhood maltreatment. J Stud Alcohol 200I, 62:486-493.

15. Jasinski JL, Williams LM, Siegel J: Childhood physical and sexual abuse as risk factors for heavy drinking among AfricanAmerican women: A prospective study. Child Abuse Negl 2000, 24: $106|-107|$.

16. Dube SR, Anda RF, Felitti VJ, Edwards VJ, Croft JB: Adverse childhood experiences and personal alcohol abuse as an adult. Addict Behav 2002, 27:713-725.

17. Downs WR, Harrison L: Childhood maltreatment and the risk of substance problems in later life. Health Soc Care Community 1998, 6:35-46.

18. Kimerling R, Baumrind $\mathrm{N}$ : Intimate partner violence and use of welfare services among California women. J Sociol Soc Welf 2004, 31:161-176.

19. Federal Register: 2002 HHS poverty guidelines. Fed Regist 2002, 67:6931-6933.

20. Prins A, Ouimette P, Kimerling R, Cameron R, Hugelshofer D, ShawHegwer J, Thrailkill A, Gusman FD, Sheikh Jl: The Primary Care PTSD Screen: Development and operating characteristics. Prim Care Psychiatry 2004, 9:9-I4.

21. Moriarty DJ, Zack MM, Kobau R: The Center for Disease Control and Prevention's Healthy Days Measures- Population tracking of perceived physical and mental health over time. Health Qual Life Outcomes 2003, I:37.

22. Norris FH: Screening for traumatic stress: A scale for use in the general population. J Appl Soc Psychol 1990, 20: 1704-1718.

23. Ebrahim SH, Diekman ST, Floyd RL, Decoufle P: Comparison of binge drinking among pregnant and nonpregnant women, United States, 199 I-1995. Am J Obstet Gynecol I999, I80:I-7.

24. Miller JW, Gfoerer JC, Brewer RD, Naimi TS, Mokdad A, Giles WH: Prevalence of adult binge drinking: $A$ comparison of two national surveys. Am J Prev Med 2004, 27:197-204.

25. Strine TW, Okoro CA, Chapman DP, Balluz LS, Ford ES, Ajani UA, Mokdad $\mathrm{AH}$ : Health-related quality of life and health risk behavior among smokers. Am J Prev Med 2005, 28:182-187.

26. Tsai J, Floyd R, Green P, Boyle C: Patterns and average volume of alcohol use among women of childbearing age. Matern Child Health J 2007, I I:437-445.

27. Schoen C, Davis K, Collins K, Greenberg L, Des Roches C, Abrams M: The Commonwealth Fund survey of the health of adolescent girls New York: Commonwealth Fund; 1997.

28. Pirkle EC, Richter L: Personality, attitudinal and behavioral risk profiles of young female binge drinkers and smokers. J Adolesc Health 2006, 38(I):44-54.

29. Wang J, Patten SB: Alcohol consumption and major depression: Findings from a follow-up study. Can J Psychiatry 200I, 46:632-638.

30. Dunne FJ, Galatopoulos C, Schipperheijn JM: Gender differences in psychiatric morbidity among alcohol misusers. Compr Psychiatry 1993, 34:95-101.

31. Kilpatrick DG, Acierno R, Resnick HS, Saunders BE, Best CL: A 2year longitudinal analysis of the relationships between violent assault and substance use in women. J Consult Clin Psychol 1997, 65:834-847.

32. Miranda JJ, Vilchez E: So simple and so meaningful: An approach to mental health after violence. J Epidemiol Community Health 2002, 56:642.

33. Rice C, Mohr CD, Del Boca FK, Mattson ME, Young L, Brady K, Nickless C: Self-reports of physical, sexual and emotional abuse in an alcoholism treatment sample. J Stud Alcohol 200I, 62:114-123.

34. Testa M, Livingston JA, Leonard KE: Women's substance use and experiences of intimate partner violence: A longitudinal investigation among a community sample. Addict Behav 2003, 28: $1649-1664$.

35. Jacobsen LK, Southwick SM, Kosten TR: Substance use disorders in patients with posttraumatic stress disorder: A review of the literature. Am J Psychiatry 200 I, I 58: I I84-I I 90.

36. Stewart $\mathrm{SH}$ : Alcohol abuse in individuals exposed to trauma: A critical review. Psychol Bull 1996, I 20:83-II2.
37. Nishith P, Resick PA, Mueser KT: Sleep difficulties and alcohol use motives in female rape victims with posttraumatic stress disorder. J Trauma Stress 200I, I4:469-479.

38. Stewart SH, Conrod PJ, Samoluk SB, Pihl RO, Dongier M: Posttraumatic stress disorder symptoms and situation-specific drinking in women substance abusers. Alcohol Treat $Q 2000,18: 31$-47.

39. Chapman DP, Whitfield CL, Felitti VJ, Dube SR, Edwards VJ, Anda RF: Adverse childhood experiences and the risk of depressive disorders in adulthood. J Affect Disord 2004, 82:217-225.

40. Kessler R, Davis C, Kendler K: Childhood adversity and adult psychiatric disorder in the US National Comorbidity Survey. Psychol Med 1997, 27: I I0I-III 9.

41. Horwitz AV, Widom CS, McLaughlin J, White HR: The impact of childhood abuse and neglect on adult mental health: A prospective study. J Health Soc Behav 200I, 42: I84-20I.

42. Schilling EA, Aseltine RH, Gore S: Adverse childhood experiences and mental health in young adults: $A$ longitudinal survey. BMC Public Health 2007, 7:30-5I.

43. Thompson R: Mothers' violence victimization and child behavior problems: Examining the link. Am J Orthopsychiatry 2007, 77:306-3I5.

44. Whitaker RC, Orzol SM, Kahn RS: Maternal mental health, substance use, and domestic violence in the year after delivery and subsequent behavior problems in children at age 3 years. Arch Gen Psychiatry 2006, 63:55I-560.

45. Gidycz CA, Loh C, Lobo T, Rich C, Lynn SJ, Pashdag J: Reciprocal relationships among alcohol use, risk perception, and sexual victimization: A prospective analysis. J Am Coll Health 2007, 56:5-14

46. Schuckit MA: Biological, psychological and environmental predictors of the alcoholism risk: A longitudinal study. J Stud Alcohol 1998, 59:485-494.

47. Crabbe J: Alcohol and genetics: New trouble. Am J Med Genet 2002, I | 4:969-974.

48. Pickens R, Svikis D, McGue M, LaBuda M: Common genetic mechanisms in alcohol, drug, and mental disorder comorbidity. Drug Alcohol Depend 1995, 39:129-138.

49. Arata CM, Stafford J, Tims MS: High school drinking and its consequences. Adolescence 2003, 38:567-579.

50. Bellis MA, Hughes K, Morleo M, Tocque K, Hughes S, Allen, Harrison $D$, Fe-Rodriguez E: Predictors of risky alcohol consumption in schoolchildren and their implications for preventing alcoholrelated harm. Subst Abuse Treat Prev Policy 2007, 2:15-26.

5I. Sher KJ: Towards a cognitive theory of substance use dependence. In Handbook of Implicit Cognition and Addiction Edited by: Wiers R, Stacy A. Thousand Oaks, CA: Sage Publications; 2006:273-276.

52. Chard KM: An evaluation of cognitive processing therapy for the treatment of posttraumatic stress disorder related to childhood sexual abuse. J Consult Clin Psychol 2005, 73:965-97I.

53. Cloitre M, Koenen KC, Cohen LR, Han H: Skills training in affective and interpersonal regulation followed by exposure: a phase-based treatment for PTSD related to childhood abuse. J Consult Clin Psychol 2002, 70: 1067-I074.

54. Lundqvist G, Svedin CG, Hansson K, Broman I: Group therapy for women sexually abused as children: Mental health before and after group therapy. J Interpers Violence 2006, 21:1665-1677.

55. Naimi T, Brewer B, Mokdad A, Denny C, Serdula M, Markes J: Definitions of binge drinking. JAMA 2003, 289: 1636.

56. Babor TF, Steinberg K, Anton R, Del Boca F: Talk is cheap: Measuring drinking outcomes in clinical trials. J Stud Alcohol 2000, 61:55-63.

57. Dube SR, Williamson DF, Thompson T, Felitti VJ, Anda RF: Assessing the reliability of retrospective reports of adverse childhood experiences among adult HMO members attending a primary care clinic. Child Abuse Negl 2004, 28:729-737.

58. Hardt J, Rutter M: Validity of adult retrospective reports of adverse childhood experiences: Review of the evidence. Child Psychol Psychiatry 2004, 45:260-273.

59. Williams LM: Recall of childhood trauma: A prospective study of women's memories of child sexual abuse. J Consult Clin Psychol 1994, 62:1167-1176.

60. Boles SM, Joshi V, Grella C, Wellisch J: Childhood sexual abuse patterns, psychosocial correlates, and treatment outcomes among adults in drug abuse treatment. J Child Sex Abus 2005, 14:39-55. 